\title{
EUS-FNA Diagnosis Cytology of Endocrine Tumor Recurrence
} Misao Yoneda ${ }^{1 *}$, Yoshifumi S. Hirokawa ${ }^{1}$, Hiroshi Imai', Kazuki Kanayama ${ }^{1}$, Masaya Fujiwara', Nobuyuki Tanahashi", Hiroyuki Inoue ${ }^{2}$,
Reiko Takayama ${ }^{2}$, Hiroyasu Inada ${ }^{3}$ and TaizoShiraishi'

${ }^{1}$ Department of Pathologic Oncology, Institute of Molecular and Experimental Medicine, Faculty of Medicine, Mie University Graduate School of Medicine, Japan ${ }^{2}$ Department of Gastroenterology and Hepatorogy, Mie University Graduate School of Medicine, Japan

${ }^{3}$ Department of Pathology, Faculty of Pharmaceutical Science, Suzuka University of Medical Science, Japan

${ }^{4}$ Institute of Traditional Chinese Medicine, Suzuka University of Medical Science, Japan

\begin{abstract}
We examined a recurrent endocrine tumor patient who had undergone preoperative diagnosis by endoscopic ultrasound-guided fine-needle aspiration (EUS-FNA). The cytomorphology and immunostaining patterns at onset were different from those seen at recurrence, and according to WHO classification we diagnosed the former condition as well-differentiated endocrine tumor and the latter condition as well-differentiated endocrine carcinoma. Endocrine tumors show great diversity of cytomorphology according to their malignancy, and we consider that understanding this is important to conducting cytoscreening diagnosis by cytomorphology.
\end{abstract}

Keywords: Endocrine cancer; Recurrence; Salt-and-pepper chromatin; Intranuclear inclusion bodies; Spindle cells

\section{Introduction}

Pancreatic endocrine tumors are comparatively rare, accounting for approximately $1.5 \%$ to $2.0 \%$ of all pancreatic tumors $[1,2]$. Of those, $15 \%$ to $30 \%$ are non-functional tumors, of which over $60 \%$ are malignant with a 5 -year survival rate of just 30\% [3]. In our investigation we examined a patient with recurrence of non-functional endocrine tumor, performing a preoperative diagnosis based on cytomorphology and immunostaining of samples derived by EUS-FNA.

\section{Case Report}

A 60-year-old male patient underwent abdominal ultrasonography, which revealed border irregularity on the head of the pancreas, part of which comprised a solid tumor mass measuring approximately $20 \mathrm{~mm}$ in diameter. After EUS-FNA, pancreaticoduodenectomy was conducted, and the patient was diagnosed as having neuroendocrine tumor (UICC: pT4). About 2 years and 6 months later, $20 \mathrm{~mm}$ mass and $30 \mathrm{~mm}$ mass were detected in S4 and S5, respectively, in the liver, and recurrence was suspected. Liver metastasis and the remaining pancreatic body were excised.

\section{Result}

\section{Cytological findings}

FNA at the time of onset was performed using a $22 \mathrm{G}$ needle. We observed salt-and-pepper chromatin, rosette formation, nuclear eccentricity, and intranuclear inclusion bodies by Diff-Quik and Pap staining (Figure 1A). Immunostaining on cell blocks produced positive test results for CD56, synaptophysin, and chromogranin A, all giving definite diagnoses of endocrine tumor. Aspiration at the time of recurrence was performed with a $22 \mathrm{G}$ needle. We observed intranuclear inclusion bodies, nuclear positivity, sheet-like cluster (Figure 1B), anisokaryosis, cell division (Figure 1C), and spindle cells (Figure 1D) by Diff-Quik and Pap staining (Table 1).

Immunostaining on cell blocks produced a positive test result for CD56, synaptophysin, and a negative result for chromogranin A, giving a definite diagnosis of endocrine carcinoma. At the time of the onset, MIB- 1 index was $20 \%$ and CK19 was positive (Figure 2A, B). At the time of recurrence, MIB-1 index was $25 \%$ and CK19 was positive (Figure 2C, D)

\section{Discussion}

Non-functional endocrine tumors, as seen in this patient, comprise $20 \%$ to $40 \%$ of pancreatic endocrine tumors. They show no increase in blood concentrations of hormones and are clinically asymptomatic [4].

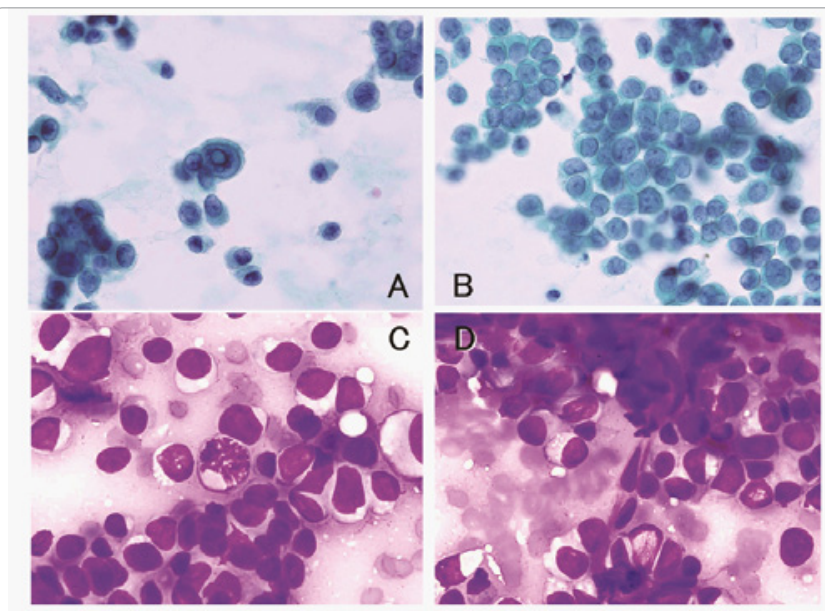

Figure 1: A: Intra-nuclear inclusion bodies by Pap (x1000). B: Sheet-like cluster of round uniform tumor cells predominate by Pap (x1000). C: Anisokaryosis, cell division by Diff-Quik (x1000). D: Spindle cells by Diff-Quik (x1000).

${ }^{*}$ Corresponding author: Misao Yoneda, Department of Pathologic Oncology Institute of Molecular and Experimental Medicine, Faculty of Medicine, Mie University Graduate School of Medicine, 2-174 Edobashi, Tsu, Mie 514-8507, Japan, Tel: +81-59-232-2864; Fax: +81-59-231-5210; E-mail: yonedam@doc. medic.mie-u.ac.jp

Received December 31, 2011; Accepted February 28, 2012; Published March 01,2012

Citation: Yoneda M, Hirokawa YS, Imai H, Kanayama K, Fujiwara M, et al. (2012) EUS-FNA Diagnosis Cytology of Endocrine Tumor Recurrence. J Cytol Histol 3:131. doi:10.4172/2157-7099.1000131

Copyright: @ 2012 Yoneda M, et al. This is an open-access article distributed unde the terms of the Creative Commons Attribution License, which permits unrestricted use, distribution, and reproduction in any medium, provided the original author and source are credited. 
Citation: Yoneda M, Hirokawa YS, Imai H, Kanayama K, Fujiwara M, et al. (2012) EUS-FNA Diagnosis Cytology of Endocrine Tumor Recurrence. J Cytol Histol 3:131. doi:10.4172/2157-7099.1000131

Thus, early discovery by PET, CT, EUS-FNA or other types of imaging or cytoscreening is considered to be important.

Important indicators in cytoscreening for endocrine tumors are scattered cells, inclusion body cells, rosette formation, nuclear eccentricity, and salt-and-pepper chromatin morphologies. It has been reported that these cytomorphologies show clearly different cytological findings from those of adenocarcinoma and STPN [5,6]. We also observed these cytomorphologies in this patient at the time of onset, which we were able to diagnose through cytoscreening by Diff-Quik and Pap staining. At recurrence, in addition to the above-mentioned cytological findings, we also observed a variety of other cytological findings, such as nuclear positivity, spindle cells, cell division, inclusion body cells, and papillary growth. The difference in tumor cytomorphology between onset and recurrence is considered to be related to the malignancy of endocrine tumors. Mai et al. [7] carefully examined cytological findings in 30 pancreatic endocrine tumor patients, but because the cytological findings for well-differentiated

\begin{tabular}{|c|c|c|}
\hline cytomorphology & at the time of onset & recurrence \\
\hline nuclear eccentricity & + & + \\
\hline scattered & + & + \\
\hline rosette formation & + & + \\
\hline salt-and-pepper chromatin & + & + \\
\hline inclusion bodies & + & + \\
\hline papillary growth & - & + \\
\hline sheet-like cluster & - & + \\
\hline cell mitosis & - & + \\
\hline spindle cells & - & + \\
\hline Nucleolus & - & + \\
\hline Immunostaining & & + \\
\hline CD56 & + & + \\
\hline Synaptophysin & + & - \\
\hline ChromograninA & + & + \\
\hline MIB-1 index & $20 \%$ & + \\
\hline CK19 & + & + \\
\hline
\end{tabular}

Table 1: At the time of onset, recurrence of Cytomorphology and Immunostaining.

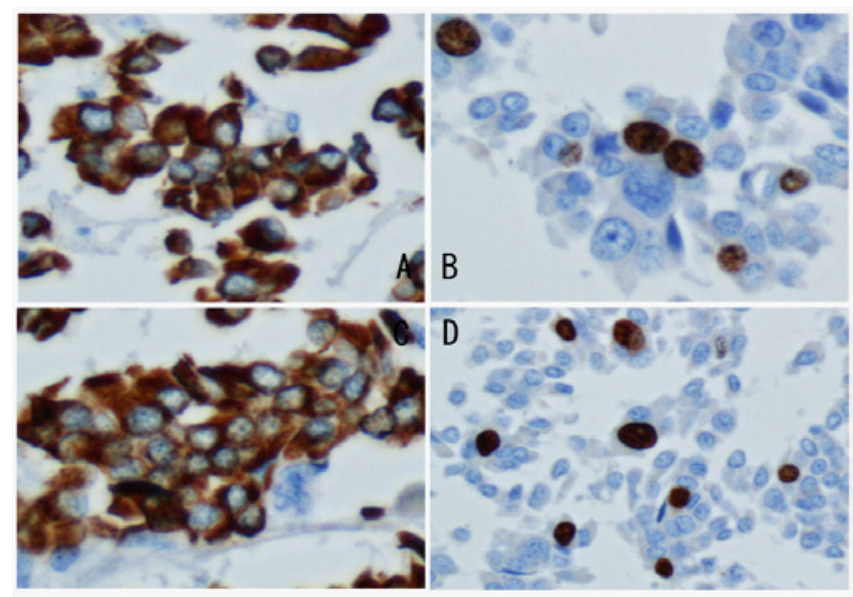

Figure 2: A: The tumor cells positive for CK19 of at the time of onset (x400). B: The tumor cells positive for MIB-1 of at the time of onset $(x 400)$. C: The tumor cells positive for CK19 of recurrence (x400). D: The tumor cells positive for MIB1 of recurrence $(x 400)$. endocrine carcinoma are also seen in other diseases besides endocrine tumor, a differential diagnostic method is necessary. We consider that the key points of cytoscreening in this case are that cells with salt-andpepper chromatin (which are an important guide for cytodiagnosis of endocrine tumor) manifest sheet-like and papillary growth and show variation and lack of binding in the periphery of cell clusters. The observation of inclusion body cells at both onset and recurrence appears to be a cytological characteristic of this case and may be useful in cytoscreening of endocrine tumors.

Chromogranin A, synaptophysin, and cell adhesion molecule CD56 are typical markers of endocrine tumor. These markers can be diagnostic of tumor formation depending on tumor differentiation. In cases of endocrine tumor, synaptophysin and CD56 test positive with great frequency, regardless of malignancy or differentiation, but chromogranin A may sometimes test negative [8]. At the time of recurrence, the case we examined showed a positive test result both for synaptophysin and CD56, but a negative result for chromogranin A. These results appear to match with the cytomorphology that indicates endocrine carcinoma at recurrence. These evidences of tumor hormone production are often obtained by using operation materials to determine the malignancy of tumors, but we consider that by placing cell samples collected by EUS-FNA on cell blocks, it is possible to make a preoperative classification of the disease condition. Vikram et al. [9] reported that MIB-1 and CK19 are effective for the malignancy grade and prognostic factor of pancreatic neuroendocrine tumor $[10,11]$. In this case, the results of immunostaining at the time of the onset indicated that MIB-1 index was $20 \%$ and CK19 was positive, and so it was considered that when strong cellular atypia is detected through the cytoscreening at the time of the onset, it is possible to predict prognosis by conducting the immunostaining of MIB-1 and CK19.

The cellular morphology of this case showed great diversity and could be useful for the classification of endocrine tumors. We believe that continued research with more such cytologically diverse cases is necessary.

\section{References}

1. Kimura W, Kuroda A, Morioka Y (1991) Clinical pathlogy of endocrine tumor of the pancreas. Analysis of autopsy cases. Dig Dis Sci 36: 933-942.

2. Gumbs AA, Moore PS, Falconi M, Bassi C, Beghelli S, et al. (2002) Review of the clinical, histologycal, and molecular aspect of pancreatic endocrine neoplasma. J Surg Oncol 81: 45-53.

3. Modlin IM, Tang LH (1997) Approahes to the diagnosis of gut neuroendocrine tumors: the last word (today). Gastroenterology 112: 583-590.

4. Chang F, Chandra A, Culora G, Mahadeva U, Meenan J, et al. (2006) Cytologic diagnosis of pancreatic endocrine tumors by endoscopic ultrasound-guided fine-needle aspiration: a review. Diagn Cytopathol 34: 649-658.

5. Hruban RH, Pitman MB, Klimstra DS (2007) Tumors of the Pancreas. AFIP Atlas of Tumor Pathology, Series 4, Fascicle 6. Washington DC: American Registry of Pathlogy, 422.

6. Naresh KN, Borges AM, Chinoy RF, Soman CS, Krishnamurthy SC (1995) Solid and papillary epithelial neoplasm of the pancreas. Diagnosis by fine needle aspiration cytology in four cases. Acta Cytol 39: 489-493.

7. Gu M, Ghafari S, Lin F, Ramzy I (2005) Cytological diagnosis of endocrine tumors of the pancreas byendoscopic ultrasound-guided fine-needle aspiration biopsy. Diagn Cytopathol 32: 204-210.

8. DeLellis RA, Lloyd RV, Heitz PU, Eng C (2004) Pathology and Genetics of Tumours of Endocrine Organs. WHO Classification of Tumours, Volume 8 . Lyon: IARC Press. 320. 
Citation: Yoneda M, Hirokawa YS, Imai H, Kanayama K, Fujiwara M, et al. (2012) EUS-FNA Diagnosis Cytology of Endocrine Tumor Recurrence. J Cytol Histol 3:131. doi:10.4172/2157-7099.1000131

Page 3 of 3

9. Deshpande V, Fernandez-del Castillo C, Muzikansky A, Deshpande A, Zukerberg L, et al. (2004) Cytokeratin 19 is a powerful predictor of survival in pancreatic endocrine tumors. Am J Surg Pathol 28: 1145-1153.

10. Schmitt AM, Anlauf M, Rousson V, Schmid S, Kofler A, et al. (2007) WHO 2004 criteria and CK19 are reliable prognostic markers in pancreatic endocrine tumors. Am J Surg Pathol 31: 1677-1682.

11. Salla C, Konstantinou P, Chatzipantelis $P$ (2009) CK19 and CD10 expression in pancreatic neuroendocrine tumors diagnosed by endoscopic ultrasoundguided fine-needle aspiration cytology. Cancer 117: 516-521. 